\title{
chapter The Changing Roles \\ 10 of the Professions in Psychiatry and Mental Health: Psychiatric (Mental Health) Nursing
}

\author{
Kevin Gournay and Peter Carter
}

\section{Introduction}

To begin - a word about the term psychiatric (mental health) nursing. In this chapter, we use the term 'mental health nursing' as this is the legal term to describe the profession. A UK Department of Health review in 1994 recommended: 'the title of mental health nurse be used both for nurses who work in the community and for those who work in hospital and day services'. 'Indeed, both authors who were once 'registered mental nurses' became 'registered mental health nurses'. Nevertheless, the terms 'psychiatric nurse' and 'community psychiatric nurse' (CPN) are still in common usage. The 1994 change in terminology was but part of a move to change the more general language used in psychiatry, leaving us with a somewhat oxymoronic term to describe what we do for people with psychiatric problems. In some parts of the chapter (particularly in describing the pre-1994 period), we refer to psychiatric nursing rather than mental health nursing.

This chapter describes some of the changes and key events that have taken place in this fifty-year period so as to illustrate the nature of the history. We therefore describe:

- Psychiatric nursing in the 1960 s.

- The development of community mental health nursing.

- A profession characterised by an increase in skills and knowledge: nurses as therapists, prescribers, researchers.

- Inpatient care.

- Nurses and other psychiatric professionals.

\section{Psychiatric Nursing in the 1960s}

Both authors commenced their career in psychiatric nursing in the late 1960s and are therefore able to offer their observations and commentary on the changes in their profession over this fifty-year period. For readers interested in a complete history of the profession from the sixteenth century to the 1990s, there is perhaps no more authoritative account than that of Professor Peter Nolan. ${ }^{2}$

When we began our careers in the large asylums, in one sense it was like stepping back in time (see also Chapter 6). We were vaguely aware that the care and treatment of the mentally ill was undergoing what, with the benefit of hindsight, were enormous changes - such changes being so well described in Anthony Clare's landmark book Psychiatry in Dissent. ${ }^{3}$ However, as mere student nurses at the bottom of a hierarchy, we were largely unaware of the detail of these changes, particularly because the wards where we began our careers were characterised 
by the use of rigid routines and a uniformity of approach. The medical superintendent still reigned, with doctors most certainly seen as a different species to nurses. The wards where we worked were dormitory-style, often overcrowded, with little space for personal possessions and certainly - for most patients - little privacy. Some hospitals had wards of up to 100 patients; many had central dining rooms and in some cases central bathing facilities, where patients would troupe up once or twice a week for a bath or a shower. One of us recollects a charge nurse appointed to do nothing else but supervise bed-making - this task then being delegated to several long-stay patients. Charge nurses (and ward sisters on the female side of the hospital - the integration of male and female patients only beginning slowly at the end of the 1960s) supervised the cleaning and other domestic duties carried out by patients. Ward domestic staff only began to appear in the late 1960s; in some hospitals, later. As this was the era just after National Service, many of the male charge nurses had served in the military, and thus an ethos of authority pervaded the atmosphere of the wards. Ward sisters were similarly figures of authority. Our female counterparts were chastised for any incorrect wearing of their uniform, starched aprons still being the order of the day. It took many years more for uniforms to disappear from psychiatric inpatient care settings - the revolution to the wearing of 'mufti' not really beginning until the mid-1970s.

Many of the patients that we looked after were totally institutionalised, and in some of the 'long-stay wards' where we worked, we had little or no conversations with many of our patients. They were often over-medicated with chlorpromazine, haloperidol and similar drugs; many incapacitated by Parkinsonian symptoms. Some of the locked wards had 'airing courts' where patients would either stand and stare at nothing in particular or stride around apace with what, on reflection, was akathisia, the interminable restlessness caused by phenothiazine tranquillisers.

Patients were provided with a range of social and recreational outlets, including the hospital cinema and once-a-week dances, where the male and female patients could mix under supervision. Most hospitals had a patient football and cricket team, with games organised between hospitals. Musical patients joined the hospital band and many hospitals put on pantomimes (one for staff and one for patients). All of these activities came within the responsibility of a member of nursing staff who was often given the title 'activities coordinator'. Such was the importance of this role that these nurses were employed at ward sister/charge nurse grade or above.

On the wards, within a few short weeks, we witnessed many patients receiving electroconvulsive therapy (ECT) for their depression or acute psychosis, and some patients who were deemed to require 'building up' were given morning courses of modified insulin therapy, with the 1960s seeing the era of insulin coma therapy falling into disuse. Those of us who began nursing in the 1960s also remember patients being treated with modified narcosis, that is, being medicated with barbiturates so that sleep prevailed for much of the 24-hour period. Any sense of patient empowerment or 'user involvement' was years away.

Some of our experiences in the three years of training to become registered nurses involved placements in industrial therapy units within the hospital, where patients often worked thirty hours a week or more, for derisory levels of pay. It was here that one might find a 'technical instructor'. Through the 1960s, hospitals began to employ occupational therapists; they were few in number but not as rare as clinical psychologists (179 in 1960; that number rising to 399 in 1970 and nearly 9,000 in 2010). ${ }^{4}$ In the 1960s, the value of work became formally recognised as a method of rehabilitating the seriously mentally ill inspired by a number of psychiatrist pioneers, notably Dr Douglas Early, ${ }^{5}$ who developed 
one of the first industrial therapy units in Bristol. All patients who could work did so. Hospitals were often relatively self-sufficient with various workshops. In 1960, some hospitals ran thriving farms; indeed, until the 1970s, the NHS employed shepherds and farm hands to work alongside 'farm nurses' to oversee the work of the patients. These farms fell into disuse and were sold off, with proceeds going to the Exchequer rather than back into the NHS.

The 1960s were a time of full employment and some of the more able long-stay patients, whose only home was the hospital where they had resided for many years, began 'working out' in local factories and other industries. Their employers were very pleased to see workers who would do exactly what they were told and work without complaint. One of the ironies of this 'working out' population was the fact that some of these long-stay patients began to earn more money in factories than some members of the nursing staff. However, while pay for nurses was low, student and newly qualified nurses were able to aspire to being able to move into a hospital house at subsidised rent and to a full pension at fifty-five. In the late 1960s, many nurses were institutionalised themselves, with their only social outlet being the use of a staff social club in the grounds of the hospital. The 'Club' (which served alcohol at much lower prices than in pubs) was the focus of not only staff social activity but often also the social activity of their families because many hospitals were at some distance from the local town. Male staff were encouraged to join the hospital's football and cricket teams. In the London area, the London Mental Hospitals Sports Association ran a football league of teams formed from the staff of the many mental hospitals that ringed the London area. Some hospitals recruited nursing staff on the basis of their sporting prowess rather than any other attribute, such was the importance of the hospital team.

Nursing staff recruits, who trained in the schools of nursing that were situated in hospital grounds, came from the local area, often as part of a family tradition. Recruits also came from the Republic of Ireland and, increasingly, from a number of more distant countries, notably Mauritius, Malaysia and the Caribbean islands. At this time, nurses did not need to demonstrate the, then, marker of a good general education, that is, five GCE O levels. Nurses without GCEs would pass a General Nursing Council test that examined general literacy, numeracy and general knowledge.

In our six-week introduction to our education and training as registered mental nurses in our respective schools of nursing, we learned a great deal about the 1959 Mental Health Act and came to understand the importance of the principle of treatment as an informal patient. In the hospital, we came across doctors and nurses who were trying to effect change, but these were in a minority. Some of our nurse tutors told us about Laing, Szasz, Cooper and Goffman. However, most qualified staff had never heard about such figures and were highly disparaging about the changes that were so clearly afoot following Enoch Powell's 1961 'Water Towers speech' (see also Chapter 1). ${ }^{6}$ By then, most hospitals had smaller shortstay units, often located away from the main hospital. The late 1960s saw the first drug addiction units and the start of units where medication was not the central approach. Day hospitals were beginning to appear. Nevertheless, most nurses were still largely engaged on 'long-stay' wards with their time spent in supervising activities of daily living and ensuring that good order prevailed. The growth of district general hospital psychiatric units was to follow from the mid-1970s onwards.

The idea that psychiatric nursing would one day become an all-graduate profession, or, indeed, a profession in its true sense at all, never crossed anyone's mind. In the 1960s, none of us envisaged a future where we could become 'responsible clinicians' under the Mental 
Health Act, independent prescribers of medicine or leaders of multidisciplinary teams that included consultant psychiatrists. Neither did we envisage a future when psychiatric nurses rose to other positions of influence and importance - for example, becoming chief executives of sprawling mental health trusts, responsible for managing budgets of many millions of pounds, leading national initiatives or chairing the development of NICE guidelines.

\section{The Development of Community Psychiatric Nursing}

In 1954, two psychiatric nurses who were working in a large psychiatric hospital, Warlingham Park in Surrey, were seconded to provide outpatient care and to assist patients discharged from the hospital to establish themselves in the community. This initiative was followed by the development of a service from Moorhaven Hospital in Devon in 1957. As White has described, ${ }^{7}$ community psychiatric nursing slowly developed and, by 1973 , formal training for CPNs was established, with a first course at Chiswick College in London. The development of long-acting (depot) injections of antipsychotic medications led to an increase in the number of CPNs. ${ }^{8}$ To begin with, the role of the CPN was simply to administer the injection. However, it quickly became apparent that extrapyramidal side effects were a problem and the role of the CPN expanded to the monitoring of side effects, alongside taking more responsibility for the assessment of mental state and risk. On a more negative note, CPNs were delegated to running depot clinics, where literally dozens of patients would attend at a time for their fortnightly injection and spend only a brief period with the nurse. While these patients were in receipt of medications that would be of some benefit, the brief interactions with the CPNs did little to provide the patient and, importantly, the family with any meaningful input to address social or psychological needs.

CPN practice began to change in the 1970s, and by the 1980s many CPNs began to base themselves in primary care settings with GPs and work largely with people with common mental disorders, such as general anxiety, relationship difficulties and 'stress'. A survey of CPNs in England in 1989 showed that one-quarter of CPNs did not have a single client with a diagnosis of schizophrenia on their caseload. ${ }^{9}$ The CPN interventions used could be described as counselling rather than any specific evidence-based approach. From the early 1990s, the practice of CPNs took another turn, with CPNs returning to a focus on people with serious and enduring mental illness, such as schizophrenia. This renewed focus was prompted by the results of two research trials. One randomised controlled trial of CPNs in primary health care in North London showed that CPN intervention produced little or no benefit. ${ }^{10}$ An economic analysis, based on that trial, demonstrated that, per unit of health gain, $\mathrm{CPN}$ interventions yielded far fewer benefits than interventions with patients with schizophrenia. ${ }^{11}$ At the same time, another trial, in Manchester, demonstrated that training CPNs to undertake psychosocial interventions with families caring for a relative with schizophrenia provided benefits to families. This CPN intervention also led to an improvement in both positive and negative symptoms in patients, with some evidence that CPN intervention reduced inpatient episodes. ${ }^{12}$ Thus began an era that extends to the present, where a large majority of CPN work is focused on people with serious and enduring illnesses. The scope of training for CPNs widened to include mental state and risk assessments and a range of psychosocial interventions, including cognitive behaviour therapy and family interventions. Thus, by the early 2000s, CPNs had become a central resource in delivering high-quality community care, with important roles in crisis intervention and early intervention teams. 
The wide dissemination of this work owes a great deal to the Sir Jules Thorn Trust, a charity that, in or around 1990, provided substantial funds to develop training in psychosocial interventions for CPNs at the Institute of Psychiatry, Psychology and Neuroscience, King's College London and the University of Manchester; this being originally known as the 'Thorn Nurse Programme'. ${ }^{13}$ The programme was disseminated across the UK and then increasingly opened up to all mental health professionals. Thorn has evolved into the multidisciplinary training provided to community mental health teams in 2020. From its beginnings in 1990, Thorn nurse training was led by a multidisciplinary group that included one of the pre-eminent figures in psychiatry at the time, Dr Jim Birley, who had been Dean of the Institute of Psychiatry. Jim Birley was generous with his time and took a great interest in not only the programme but all those involved. As this chapter reflects throughout, many of the very positive developments in psychiatric nursing owe much to the contribution of a number of psychiatrists who have recognised the importance of the nursing profession in the care of the mentally ill.

\section{A Profession Characterised by an Increase in Skills, Knowledge and Responsibility}

Between 1960 and 2010, there were significant developments in the education and training of mental health nurses. The syllabus for mental health nurse training was updated in 1964 to include psychology and sociology for the first time. It also suggested that student nurses should spend some time outside their hospital on community placements. This represented a major break with traditional training, which had been geared solely towards preparing nurses for work within institutions. By the turn of the century, all preregistration training was located in universities - the hospital training schools having closed in the early 1990s. By 2000, the syllabus covered a wide range of topics, both theoretical and practical, with an emphasis on evidence-based approaches. ${ }^{14}$ By 2010, degree-level education required students to acquire a breadth and depth of knowledge that was in great contrast to their counterparts in 1960. While their time in clinical placements was more limited, they were expected to critically analyse and reflect on the clinical practice that they observed. There was also a growing expectation that a significant number of the student body would go on to further study, with growing numbers expected to complete further training to equip them with specialist skills and some to continue on to master's level.

Arguably, one of the most influential figures in the development of specialist nurse roles was Professor Isaac Marks, a distinguished psychiatrist rather than a nurse. Marks's career has been devoted to three central topics: first, the adherence to an evidence-based approach for all that we do in psychiatry; second, the development of methods for treating common mental disorders (particularly those that cause considerable handicap, e.g. obsessivecompulsive disorder (OCD) and severe agoraphobia); and, finally, innovations that could extend treatment to wider populations. Marks was one of the first to develop computer assisted treatments for common mental disorders. ${ }^{15}$ As a young psychiatrist, not long in the UK from South Africa and then at the Maudsley Hospital/Institute of Psychiatry, he identified the core elements of effective behavioural treatment for anxiety disorders, notably phobias and OCD. These core elements were exposure and, in the case of OCD, response prevention. ${ }^{16}$ Marks also realised that these therapies were, in one sense, the domain of practice of clinical psychologists. However, on the other hand, psychologists were few in number and it was clear that this workforce would be unable to deliver treatment to the tens, 
or hundreds, of thousands of patients who might be responsive to these new psychological treatments. He realised that psychiatric nurses might be suitable for training in these methods, particularly because of their background general experience of dealing with people with a wide variety of mental health problems in various settings. Thus, in 1972, Marks began the Nurse Therapy training programme. Over a pilot programme lasting three years, he developed a rigorous training for nurses to become autonomous therapists. The results of this study and subsequent research demonstrated very clearly that, both clinically and economically, nurses could be effective autonomous therapists. ${ }^{17}$ From 1975 onwards, Nurse Therapy Training (a full-time course of eighteen months) led to the graduation of literally hundreds of nurses from sites in the UK and the Republic of Ireland. Arguably, this programme seeded the developments for more widespread training in psychological methods, culminating in the Improving Access to Psychological Therapies programme that began in 2006, in which nurses have played leading roles in development, education, evaluation and dissemination. ${ }^{18}$

In another enormous change in the responsibilities of psychiatric nurses, the year 1992 saw changes in legislation which meant that nurses were able to prescribe from an extended formulary. Following a number of policy reviews and with a change in the NHS landscape, ${ }^{19}$ the law was changed so that, following an approved and comprehensive training programme, independent nurse prescribers would be able to prescribe any licensed medicine for any medical condition, providing it was within their expertise. Thus, towards the end of the period covered by this chapter, psychiatric nurses across the country were beginning to receive such training and the requisite legal authority. In practice, this meant, for example, that an independent nurse prescriber could make changes to the patient's medication, thus enabling psychiatrists to spend more time with patients whose needs were complex and who might have significant physical comorbidities. Overall, nurse prescribing was welcomed by the psychiatric profession. However, some opposition has come from nursing academics, who objected to nurses being enveloped by the 'medical model'. ${ }^{20}$ By 2010 , it became clear that, while mental health nurse prescribing was growing slowly, the way in which nurse prescribing was used across the NHS varied considerably and there was still some disagreement regarding the most appropriate settings for this work. ${ }^{21}$

In 2007, the Mental Health Act was amended so that nurses could become a 'responsible clinician' or an 'approved mental health professional', important roles in the supervision and safeguarding of the rights of patients subject to the involuntary provisions of the Act. These legal changes were prompted by the fact that CPNs had, since 1991, become 'care coordinators', with a wide range of responsibilities under the Care Programme approach. ${ }^{22}$

In another development that followed improvements in the education and training of psychiatric nurses, they acquired sufficient skills to be able to lead and conduct research trials that would meet the standard required of high-impact psychiatric journals. Thus, in the same edition of the British Journal of Psychiatry in 1994, the results of two research trials involving CPNs were published, both led by graduates of Marks's Nurse Therapy Programme. ${ }^{23}$ By the year 2000, the Medical Research Council had begun the funding of postdoctoral fellowships for mental health nurses. This enabled nurses who already had a $\mathrm{PhD}$ and some research training to go on to complete postdoctoral courses in subjects such as epidemiology, statistics and trial design. Towards the end of the first decade of the present century, psychiatric nurses began to figure in the range of research studies funded by the National Institute of Health Research (NIHR). By this time, nurses had also begun to take leading parts in the National Institute for Health and Care Excellence (NICE) and the 
Cochrane Collaboration. The year 1995 saw the inauguration of the first chair in psychiatric nursing at the Institute of Psychiatry/Maudsley Hospital. This development was due to the efforts of Sir David Goldberg, at that time Professor of Psychiatry, who had become a great friend to nursing some years before in Manchester as a collaborator on the aforementioned trial of training nurses in psychosocial interventions. ${ }^{24}$

\section{Changes in the Nursing of Inpatients}

In 1960, there were around 150,000 patients in the large mental hospitals; by 2010, there were $23,000 .{ }^{25}$ The reduction in bed numbers over the years resulted in nurses needing to provide care for a population with acute episodes of illness that posed significant challenges for nursing staff. Many patients had the additional problem of drug and alcohol use. Two important problems had become the source of great concern: patient suicide and violence. The National Confidential Inquiry into Suicide and Homicide by People with Mental Illness (established in 1996) published its first report, Safety First, in $2001 .^{26}$ This reported that 16 per cent of all inquiry cases of suicide in England were psychiatric inpatients. These tragic events were most likely to be by hanging, most commonly from a curtain rail and using a belt as a ligature. Wards were also seeing higher levels of violence. ${ }^{27}$

The NHS responded to the matter of inpatient suicide by spending vast sums on making wards safer, resulting in a great reduction in suicide rates. ${ }^{28}$ At the same time, three nursing bodies, the United Kingdom Council for Nursing Midwifery and Health Visiting (the predecessor body to the Nursing and Midwifery Council); the Royal College of Nursing and the Standing Nursing Midwifery Advisory Committee for the UK responded to the challenge with a number of surveys, literature reviews, visits to services and consultations with all interested parties to begin developing recommendations for changing nursing practice. Eventually NICE guidelines on the management of disturbed and violent behaviour in mental health and emergency settings were published in $2005,{ }^{29}$ with the guidelines leading to much-improved standards for the observation of patients at risk and improved training in the prevention and management of violence.

\section{Nursing and Other Professions in Psychiatric Settings}

As noted, and for a range of reasons, in 1960 nurses were at the very bottom of a hierarchy. In 2010, most newly qualified nurses were graduates and could go on to develop a wide range of specialist skills. Importantly, the remuneration for nurses was, in relative terms, much improved. A nurse qualifying in 2010 could aspire to become a nurse consultant, a director of nursing or an NHS Trust chief executive. While pay is still a contentious issue, senior nurses earn salaries that are within the same range as social workers, occupational therapists and psychologists.

In clinical settings, by 2010 many clinical services and multidisciplinary teams were led by nurses. By this time, nurses were performing roles that had, only a few years before, belonged to other disciplines - for example, providing high-quality psychological treatments, prescribing medication or making recommendations in respect of detention in hospital. Arguably, this blurring of roles made for a more harmonious approach to patient care, with nurses, by 2010, being highly skilled and much-respected members of the professional psychiatric community. 


\section{Conclusion}

It would not be an exaggeration to say that, in comparison with all other professions in psychiatry, nursing changed beyond recognition between 1960 and 2010. Nurses became members of an established profession. Over the years, the profession saw the acquisition of a wide range of knowledge and skills that in most ways have reflected the changing landscape in psychiatry, notably following the closure of the large hospitals. The question now posed is, what changes will take place in our profession in years to come?

\section{Key Summary Points}

- Psychiatric (mental health) nursing is a relatively young profession that developed with great speed over this fifty-year period. In 1960, nearly all nurses were employed in large mental hospitals.

- While education and training were improving, nurses' roles in the 1960s largely involved the care and supervision of institutionalised patients. The pay and status of nurses were low, with nursing at the bottom of a medically led hierarchy.

- The 1970s saw a great expansion in community psychiatric nursing; the development of Nurse Therapy training; and the gradual emergence of multidisciplinary teams.

- The education and training of nurses improved, as did pay conditions and status; and by 2010, nursing was becoming an all-graduate profession.

- The end of the era saw nurses becoming independent prescribers and skilled clinicians. Changes in the Mental Health Act meant that nurses could assume additional roles by becoming 'responsible clinicians' or 'approved mental health professionals'.

\section{Notes}

1. Department of Health, Working in Partnership. London: HMSO, 1994.

2. P. Nolan, A History of Mental Health Nursing. London: Stanley Thornes, 1993.

3. A. Clare, Psychiatry in Dissent: Controversial Issues in Thought and Practice. London: Tavistock, 1976.

4. J. Turner, R. Hayward, K. Angel et al., The history of mental health services in modern England: Practitioner memories and the direction of future research. Medical History (2015) 59: 599-624.

5. D. Early, The Industrial Therapy Organisation (Bristol): A development of work in hospital. The Lancet (1960) 2: 754-7.

6. J. E. Powell, Speech by Rt hon Enoch Powell; Report of the National Association for Mental Health Conference, 1961.

7. E. White, Community mental health nursing: An interpretation of history as a context for contemporary research. In J. Macintosh, eds, Research Issues in Community Nursing (Community Healthcare Series). London: Palgrave, 1999.

8. J. Bennett, J. Done, P. Harrison-Reed and B. Hunt, Development of a rating scale/checklist to assess the side effects of antipsychotics by community psychiatric nurses. In C. Brooker and E. White, eds, Community Psychiatric Nursing: A Research Perspective, Vol. 2. London: Chapman \& Hall, 1995.

9. White, Community mental health nursing.

10. K. Gournay and J. Brooking, The CPN in primary health care: An outcome study. British Journal of Psychiatry (1994) 165: 231-8. 
11. K. Gournay and J. Brooking, An economic analysis of the work of mental health nurses in primary care. Journal of Advanced Nursing (1995) 22: 769-78.

12. C. Brooker, I. Falloon, A. Butterworth, D. Goldberg, V. Graham-Hole and R. Hillier, The outcome of training community psychiatric nurses to deliver psychosocial interventions. British Journal of Psychiatry (1994) 165: 222-30.

13. C. Gamble, The Thorn Nurse training initiative. Nursing Standard (1995) 9: 31-4.

14. R. Newell and K. J. M. Gournay, Mental Health Nursing: An Evidence-Based Approach (2nd ed.). Edinburgh: Churchill Livingstone, 2009.

15. I. Marks, K. Cavanagh and L. Gega, Hands-on-Help: Computer Aided Psychotherapy. New York: Psychology Press, 2007.

16. I. M. Marks, Fears Phobias and Rituals. Oxford: Oxford University Press, 1987.

17. I. Marks, Nurses As Therapists in Primary Care. London: RCN Publications, 1985.

18. D. M. Clark, R. Layard, R. Smithies, D. A. Richards, R. Suckling and B. Wright, Improving access to psychological therapy: Initial evaluation of two UK demonstration sites. Behaviour Research and Therapy (2009) 47: 910-20.

19. K. J. M. Gournay and R. Gray, Should mental health nurses prescribe? Maudsley Discussion Paper No. 11, Institute of Psychiatry, London, 2001.

20. P. Barker and P. Buchanan-Barker, First, do no harm: Confronting the myths of psychiatric drugs. Nursing Ethics (2012) 19: 45-63.

21. D. Dobel-Ober, N. Brinblecombe and E. Bradley, Nurse prescribing in mental health: A national survey. Journal of Psychiatric and Mental Health Nursing (2010).

22. Department of Health. The Care Programme Approach for People with a Mental Illness. London: Department of Health, 1990.

23. Gournay and Brooking, The CPN in primary health care; Brooker, Falloon, Butterworth et al., The outcome of training community psychiatric nurses to deliver psychosocial interventions.

24. Brooker, Falloon, Butterworth et al., The outcome of training community psychiatric nurses to deliver psychosocial interventions.

25. Turner, Hayward, Angel et al., The history of mental health services in modern England.

26. Safety First: Report of the National Confidential Inquiry into Suicides and Homicides by People with a Mental illness. University of Manchester, 2001.

27. S. Wright, R. Gray, J. Parkes and K. J. M. Gournay, The prevention and therapeutic management of violence in acute in patient psychiatry: A literature review and evidence based recommendations for good practice. Review for United Kingdom Council for Nursing Midwifery and Health Visiting. London: NMC Library, 2002.

28. K. J. M. Gournay, Patient safety: Reducing harm and saving lives. British Journal of Mental Health Nursing (2014) 3: 96-7.

29. NICE, Violence: The Short-Term Management of Disturbed/Violent Behaviour in Psychiatric In-patient Settings and Emergency Departments. Clinical Guideline 25. London: NICE, 2005. 